\title{
Analysis of Dental Practitioners Perception Towards Dental Implants
}

Naseer Ahmed ${ }^{1}$

Maria Shakoor Abbasi ${ }^{2}$

Quratulain Mariam ${ }^{3}$

Hanan William ${ }^{4}$

Hafsa Iftikhar ${ }^{5}$

Hamna Badar ${ }^{6}$

Adil Bin Irfan ${ }^{7}$

\author{
BDS, FCPS \\ BDS, FCPS \\ BDS, MBA \\ BDS \\ BDS \\ BDS \\ BDS
}

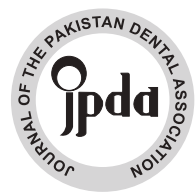

OBJECTIVE: To investigate the dental practitioner's knowledge, attitude and practice towards dental implants.

METHODOLOGY: This study was carried out from May'2019 - Oct 2019. 752 dental practitioners who were currently practicing were included in the study. A well-structured questionnaire was used for data collection. SPSS-25 was used for statistical analysis. Spearman correlation was used to find the effect of gender, knowledge and attitude. The P $\leq 0.05$ was considered statistically significant.

RESULTS: In this study $80.9 \%$ dental practitioners were aware of the appropriate implant material while, $57.9 \%$ had knowledge about the types. $30.3 \%$ knew about the implant surface modifications whereas $46.1 \%$ dentists were aware of possible implant placement approaches. $49.3 \%$ believed that the distance between dental implants to be $3 \mathrm{~mm}$ and between a dental implant and natural tooth to be $1.5 \mathrm{~mm}$. $76 \%$ dentists claimed that dental implants have biomechanical complications. Whereas $67.8 \%$ knew about the Branemark's theory of osseointegration. Regarding the attitude of dental practitioners, $28.9 \%$ had received implant hands on trainings while $9 \%$ felt competent to place an implant.

CONCLUSION: This study describes that dental practitioners had an appropriate knowledge of each aspect of implantology. Moreover despite the fact majority felt that they are not competent enough to practice it. Thus, it is important that the curriculum, teaching standards, the materials and methods regarding dental implants need to be reviewed and more exposure of hands-on workshops is to be provided not only for the graduates but also the undergraduates during their clinical learning. KEYWORDS: Dental Implants, Dentist's opinion, Knowledge

HOW TO CITE: Ahmed N, Abbasi MS, Mariam Q, William H, Iftikhar H, Badar H, Irfan AB. Analysis of dental practitioners perception towards dental implants. J Pak Dent Assoc 2021;30(1):45-49.

DOI: https://doi.org/10.25301/JPDA.301.45

Received: 12 August 2020, Accepted: 21 November 2020

\section{INTRODUCTION}

$\mathrm{W}$ ithin the last few years, it seems that dentistry has recorded its most remarkable progress and dental implantology emerging as a contemporary

1. Associate Professor, Department of Prosthodontics, Altamash Institute of Dental Medicine, Karachi 75500, Pakistan.

2. Assistant Professor, Department of Prosthodontics, Altamash Institute of Dental Medicine, Karachi 75500, Pakistan.

3. Registrar, Department of Prosthodontics, Altamash Institute of Dental Medicine, Karachi 75500, Pakistan.

4. House Surgeon, Department of Prosthodontics, Altamash Institute of Dental Medicine, Karachi 75500, Pakistan.

5. House Surgeon, Department of Prosthodontics, Altamash Institute of Dental Medicine, Karachi 75500, Pakistan.

6. House Surgeon, Department of Prosthodontics, Altamash Institute of Dental Medicine, Karachi 75500, Pakistan.

7. Registrar, Department of Prosthodontics, Altamash Institute of Dental Medicine, Karachi 75500, Pakistan.

Corresponding author: "Dr. Maria Shakoor Abbasi" <maria_shakoor@hotmail.com> and essential component of dentistry around the globe. Dental implants use the process of Osseointegration to be fixed in the jaw bone and a large number of clinical studies support their long term prognosis. ${ }^{1-3}$ Using dental implants avoids the biological complications associated with fixed partial denture that requires adjacent teeth to be prepared and serve as an abutment for the bridge, since it may lead to a long term poor prognosis. ${ }^{4-6}$

With increasing demands of the patients for implant supported prostheses, dental practitioners dealing with this field of dentistry have to face with patients' high expectations concerning excellent esthetics and function. ${ }^{7}$ In addition, a dental practitioner's knowledge and attitude towards the treatment can influence the treatment planning and ultimately the oral health of an individual. The Dental practitioners 
play a vital role in educating the patients regarding their treatment needs, thus, it is essential for them to have an ample knowledge about dental implantology. ${ }^{8,9}$ In a study by Rathod et al in 2017, it was found that the knowledge and attitude of dental practitioners was limited, and it was concluded that the dental education programs could be helpful to update the knowledge regarding dental implantology. ${ }^{10}$

Furthermore similar results were found by other studies including Sheth et al and Dhami et al in which general practitioners had limited knowledge and majority showed an increased desire for knowledge in the field of implants and welcomed the suggestion of introducing implantology as a separate subject in the BDS curriculum. ${ }^{11,12}$ Moreover, till now only one study evaluated the knowledge of Dental implants amongst the dental practitioner at the national level which also showed limited knowledge and awareness about dental implants. ${ }^{13}$

To the best of authors' knowledge there is paucity of information regarding the perception and knowledge of dental implants in dental practitioners of Pakistan. Therefore, the present study was executed with the chief aim to assess the knowledge, attitude, and practice of dental implants among dental practitioners of Karachi, Pakistan.

\section{METHODOLOGY}

This cross-sectional study was conducted with informed consent, from May 2019 to October 2019. The study was approved by ethics and review committee of AIDM/EC/05/2019/15. Both male and female dental practitioners inclusive of all ages, who were currently practicing were included in the study. All those having a clinical postgraduate qualification were excluded. The sample size was calculated with Open-Epi software. Considering $(55 \%)^{12}$ prevalence of knowledge amongst dental practitioners. The estimated sample size at 3\% margin of error and $97 \%$ confidence interval was $\mathrm{n}=667$ dentists for considering the 30,000 population. The figure achieved was later overestimated to 800 participants, to attain maximum responses.

A well-structured questionnaire comprising of knowledge and attitude based questions was distributed among the dental practitioners of different dental colleges of Karachi, Pakistan. The questionnaire was divided into two sections. Section one included the demographic details. Section two was comprised of 15 close ended questions regarding Knowledge, Attitude and Practices of the participants towards dental implants. The validity of the questionnaire was checked with Cronbach's Alpha $(=0.7)$. Responses were collected through both, the hard copy and an online google form link.
SPSS-25 was used for analyzing the data and descriptive analysis was performed to determine the mean, standard deviation, frequency and percentages. Spearmen correlation test was used to find the relationship of gender with knowledge, practice and attitude level of participants. The $\mathrm{P} \leq 0.05$ was considered statistically significant.

\section{RESULTS}

In this study, out of 800 distributed questionnaires, 752 were included. 48 questionnaires were excluded based on partially filled status and repetition of response. The total number of dental practitioners targeted was 752 out of which $204(27 \%)$ were males and $548(73 \%)$ were females, with majority $717(95.3 \%)$ belonging to age bracket of 22-31 years. 631(83.9\%) were graduates, $121(16.1 \%)$ were postgraduate trainees. The results were determined, and it was found that $609(80.9 \%)$ dental practitioners were well aware of the appropriate material (Titanium) of a dental implant. 436 (57.9\%) had knowledge about all the types of implant. 421 (55.9\%) of the dental practitioners were aware of the screw-shaped dental implants, however only 228 $(30.3 \%)$ knew about the various surface modifications, as shown in (Table I).

Table I: Responses regarding the Knowledge of Participants $(n=752)$

\begin{tabular}{|c|c|c|c|c|c|c|c|}
\hline \multicolumn{2}{|c|}{ Implant Material } & \multicolumn{2}{c|}{ Implant Type } & \multicolumn{2}{c|}{ Implant Shape } & \multicolumn{2}{c|}{ Surface Texture } \\
\hline Questions & $\%$ & Questions & $\%$ & Questions & $\%$ & Questions & $\%$ \\
\hline Titanium & $\begin{array}{c}6099 \\
(80.9 \%)\end{array}$ & Submucosal & $15(2 \%)$ & Cylinder & $6(0.7 \%)$ & Hydroxyapatite & $\begin{array}{c}124 \\
(16.4 \%)\end{array}$ \\
\hline Stainless steel & $\begin{array}{c}65 \\
(8.6 \%)\end{array}$ & Sub-periosteal & $\begin{array}{c}74 \\
(9.9 \%)\end{array}$ & Serew & $\begin{array}{c}421 \\
(55.9 \%)\end{array}$ & Ceramics & 6.9 \\
$(9.2 \%)$ \\
\hline Cobalt & $0(0 \%)$ & Endosteal & $\begin{array}{c}212 \\
(28.1 \%)\end{array}$ & Hollow & $\begin{array}{c}34 \\
(4.6 \%)\end{array}$ & $\begin{array}{c}\text { Titanium Plasma } \\
\text { sprayed }\end{array}$ & $\begin{array}{c}134 \\
(17.8 \%)\end{array}$ \\
\hline All & $\begin{array}{c}78 \\
(10.3 \%)\end{array}$ & All & $\begin{array}{c}436 \\
(57.9 \%)\end{array}$ & All & $\begin{array}{c}276 \\
(36.8 \%)\end{array}$ & All & $(30.3 \%)$ \\
\hline Don't know & $0(0 \%)$ & Don't know & $15(2 \%)$ & Don't know & $15(2 \%)$ & Don't know & 197 \\
& & & & $126.3 \%)$ \\
\hline
\end{tabular}

$346(46.1 \%)$ dentists were well aware of all the possible implant placement approaches. Out of all the participants, $371(49.3 \%)$ believed the distance between two dental implants to be $3 \mathrm{~mm}$ and distance between a dental implant and a natural tooth to be $1.5 \mathrm{~mm}$ as presented in (Table II).

Table II: Responses regarding the Knowledge of Participants $(n=752)$

\begin{tabular}{|c|c|c|c|c|c|}
\hline \multicolumn{2}{|c|}{ Implant Loading } & \multicolumn{2}{c|}{ Distance between Implants } & \multicolumn{2}{c|}{$\begin{array}{c}\text { Distance between implant and } \\
\text { natural teeth }\end{array}$} \\
\hline Questions & $\%$ & Questions & $\%$ & Questions & $\%$ \\
\hline One stage & $\begin{array}{c}45 \\
(5.9 \%)\end{array}$ & $1 \mathrm{~mm}$ & $20(2.6 \%)$ & $0.5 \mathrm{~mm}$ & $\begin{array}{c}35 \\
(4.6 \%)\end{array}$ \\
\hline Two stage & $\begin{array}{c}233 \\
(30.9 \%)\end{array}$ & $2 \mathrm{~mm}$ & $\begin{array}{c}222 \\
(29.6 \%)\end{array}$ & $1 \mathrm{~mm}$ & $\begin{array}{c}114 \\
(15.1 \%)\end{array}$ \\
\hline Immediate restoration & $\begin{array}{c}34 \\
(4.5 \%)\end{array}$ & $3 \mathrm{~mm}$ & $\begin{array}{c}371 \\
(49.3 \%)\end{array}$ & $1.5 \mathrm{~mm}$ & $\begin{array}{c}371 \\
(49.3 \%)\end{array}$ \\
\hline All & $\begin{array}{c}346 \\
(46 \%)\end{array}$ & $4 \mathrm{~mm}$ & $\begin{array}{c}94 \\
(12.5 \%)\end{array}$ & $2 \mathrm{~mm}$ & $\begin{array}{c}182 \\
(24.2 \%)\end{array}$ \\
\hline Don't know & $\begin{array}{c}94 \\
(12.5 \%)\end{array}$ & Don't know & $45(5.9 \%)$ & Don't know & $\begin{array}{c}50 \\
(6.6 \%)\end{array}$ \\
\hline
\end{tabular}

The Table III showing that more than $88 \%$ of the dentists said that implant supported prostheses have better aesthetic 
and functional efficiency though they believed that it needs more oral hygiene maintenance. $n=573(76 \%)$ of the dentists claimed that dental implants have certain biological and technical complications. Whereas 510 (67.8\%) knew about the Branemark's theory of osseointegration as described in (Table III).

Table III: Responses regarding the Knowledge of Participants $(n=752)$

\begin{tabular}{|c|c|c|c|cc|c|c|c|c|}
\hline \multicolumn{2}{|c|}{$\begin{array}{c}\text { Aesthetic } \\
\text { restoration }\end{array}$} & \multicolumn{2}{|c|}{ Function restoration } & \multicolumn{2}{c|}{$\begin{array}{c}\text { Hygiene } \\
\text { maintenanee } \\
\text { preseription }\end{array}$} & \multicolumn{2}{c|}{$\begin{array}{c}\text { Biomechanical } \\
\text { failure in implants }\end{array}$} & \multicolumn{2}{c|}{$\begin{array}{c}\text { Branemark's } \\
\text { protocol of } \\
\text { Osseointegration }\end{array}$} \\
\hline Yes & No & Yes & No & Yes & No & Yes & No & Yes & No \\
\hline $\begin{array}{c}667 \\
(88.8 \%)\end{array}$ & $\begin{array}{c}85 \\
(11.2 \%)\end{array}$ & $\begin{array}{c}667 \\
(88.8 \%)\end{array}$ & $\begin{array}{c}85 \\
(11.2 \%)\end{array}$ & $\begin{array}{c}664 \\
(88.2 \%)\end{array}$ & $\begin{array}{c}88 \\
(11.8 \%)\end{array}$ & $\begin{array}{c}573 \\
(76.2 \%)\end{array}$ & $\begin{array}{c}179 \\
(23.8 \%)\end{array}$ & $\begin{array}{c}510 \\
(67.8 \%)\end{array}$ & $\begin{array}{c}242 \\
(32.2 \%)\end{array}$ \\
\hline
\end{tabular}

Regarding the attitude of dental practitioners towards a dental implant, only 218 (28.9\%) received implant hands on trainings. 223 (29\%) felt competent enough to place an implant and $668(88.8 \%)$ were the ones who attended lectures on dental implants as mentioned in (Table IV).

Table IV: Responses regarding the Attitude of Participants $(n=752)$

\begin{tabular}{|c|c|c|c|c|c|}
\hline \multicolumn{2}{|c|}{ Implant lectures attended } & \multicolumn{2}{c|}{ Competeney to place an implant } & \multicolumn{2}{c|}{ Implant hands-0n reecived } \\
\hline Yes & No & Yes & No & Yes & No \\
\hline $668(88.8 \%)$ & $84(11.2 \%)$ & $223(29.6 \%)$ & $529(70.4 \%)$ & $218(28.9 \%)$ & $534(71.1 \%)$ \\
\hline
\end{tabular}

No significant relationship was found between gender with knowledge and attitude of participants regarding dental implants ( $(\mathrm{ho}=0.016),(\mathrm{p}=0.093)$.

Though significant relationship was found between knowledge and attitude of participants regarding dental implants (rho $=0.9),(\mathrm{p}=0.025)$.

\section{DISCUSSION}

Literature reveals that conventional methods like removable dentures failed to satisfy the patients, But now, with dental implants, missing teeth can be replaced with substantial, comfortable and aesthetically pleasing artificial alternatives. ${ }^{14-17}$ According to our study, $81 \%$ of dental practitioners assured that titanium is the best material which is in accordance with Parr et al, which states that titanium is extremely stable when used in human body. ${ }^{18}$ Although Titanium has been widely used in dentistry as it is biocompatible and has excellent mechanical properties, the incidence of hypersensitivity and allergic reactions is still unknown. ${ }^{19}$ Furthermore, various dental implant types, body designs and surface modifications have been reported in the literature. ${ }^{1,8,15,19}$ In this study, $57.9 \%$ had knowledge about all the types of implant. 55.9\% of the dental practitioners were aware of the screw-shaped dental implants, however only $30.3 \%$ knew about the various surface modifications.

Around $49.3 \%$ of the dental practitioners opted $3 \mathrm{~mm}$ as inter-implant distance and $1.5 \mathrm{~mm}$ as normal distance between a tooth and an implant. Whereas in a research carried out by Ramanaurkaite, A. et al, in 2018 states that the normal interimplant distance can be from $2 \mathrm{~mm}$ to $4 \mathrm{~mm}$ depending on the reference points. ${ }^{20}$ Similarly, Jose et. al in 2004 concluded that the average distance between two implants and the average distance between an implant and a natural tooth range from $3 \mathrm{~mm}$ to $4 \mathrm{~mm}$. The research we carried out among 752 dental practitioners, only included the horizontal distance between two dental implants, unlike, the research carried out by Jose et. al, who focused not only the horizontal distance but also the vertical distance and lateral spacing. ${ }^{21}$

Taking the bio-mechanical failure of a dental implant into consideration, $76.3 \%$ of our dental practitioners reflected that an implant can surely have certain biological and technical complications if a proper diagnosis is not made and the proper technique is not used. Similarly, in a study by Liaw, $\mathrm{K}$. et al, stated that with increased use of dental implants comes an increased risk of complications, given the fact that an implantologist should be able to diagnose and recognize the complications. ${ }^{22}$ Likewise, a study done by Porter Ja, et al, on success and failure of implant showed that, there are certain primary predictors, pre and post operatively, that lead to the failure of implant. Thus, admitting the fact that loading a dental implant can surely have bio-mechanical complications . ${ }^{23}$ Another study focused on the complications associated with dental implants, i.e. mechanical complications (screw loosening, screw fracture, cement failure), technical complications (fracture of veneering porcelain, fracture of the framework in implant-supported fixed partial dentures) and biologic complications (adverse soft tissue reactions, sensory disturbances, progressive marginal bone loss, loss of integration). ${ }^{24}$

It was suggested by $88.2 \%$ of our respondents that the patients who received an implant should be more keen in maintaining their oral hygiene, this is in harmony with the study carried out by Arati Sharma et al, where 58.4\% candidates also felt the need to follow oral hygiene protocols by people with implants in their oral cavity. ${ }^{25}$

Assessing the knowledge on the basis of implant training received, we deduced that $29 \%$ of our candidates received hands-on trainings, whereas in a survey carried out by Vickie et al, in 2004 suggested that $86 \%$ of their respondents had received the training, revealing how the knowledge and attitude changed if implant dentistry curriculum was introduced as a predoctoral program. ${ }^{26}$ Regarding the competency to place an implant we concluded that $29.6 \%$ of our respondents felt competent enough to place an implant whereas in a study published by D. J. Schonwetter, stated that many of their respondents did not feel confident enough to place an implant because the respective field was given the least importance as a learning criteria. ${ }^{27}$ This is supported 
by a study conducted in various dental institutions in Pakistan regarding oral implantology education which concluded that Implant education has been introduced in most institutions during past 5-10 years only and topics such as implant prosthetics, bone regeneration and grafting are not adequately covered in implant curriculum. ${ }^{28}$ Although majority of respondents in this study $(73 \%)$ were females but there was no significant relationship found between gender with knowledge and attitude regarding dental implants; this was in line to a cross sectional study in which no significant effect of gender could be highlighted, however male respondents predominated (54.6\%). However, it has been reported that dental practitioners with implant training have an edge over those with no professional training, as it enhances the knowledge with a positive attitude and practice of dental implants. ${ }^{2}$

Since this is an era of social media and implantology is an emerging field of dentistry with widespread awareness amongst the general population, there are several aspects that need to be worked upon on part of dental professionals themselves so that better health-care services could be provided to the masses.

\section{LIMITATIONS OF THIS STUDY}

This study doesn't provide an insight regarding awareness of the distance of a dental implant to the other vital structures in oral cavity (like maxillary sinus, inferior alveolar canal, etc). Taking implant loading into consideration, one should be well aware of all the parameters which could lead to its success and failure. Future research with a larger sample size could be focused on pre-treatment evaluation and predictors of success and failure to overcome the knowledge gap.

\section{CONCLUSION}

This study describes that dental practitioners had an appropriate knowledge of each aspect of implantology. Moreover despite the fact majority felt that they are not competent enough to practice it. Therefore, the curriculum, teaching standards and methods regarding dental implants need reconsideration, exposures to hands-on workshops are necessary for the graduates and also for undergraduate students during their clinical learning

\section{ACKNOWLEDGEMENT}

The authors are grateful to research and evaluation committee Altamash Institute of Dental Medicine for support and facilitation in this study.

\section{CONFLICT OF INTEREST}

The authors declared no conflict of interest

\section{REFERENCES}

1. Block MS. Dental implants: The last 100 years. J Oral Maxfac Surg. 2018:1;76:11-26.

https://doi.org/10.1016/j.joms.2017.08.045

2. Nagpal D, Prakash S, Kalra DD, Singh G. Knowledge, attitude, and practice of dental implants among dental postgraduates and practitioners in Davangere City, Karnataka: A cross-sectional study. Indian J Dent Res. 2018:575-82.

https://doi.org/10.4103/ijdr.IJDR_500_15

3. Abbasi MS, Rahim S, Qureshi AW, Sharif M, Shah R, Minallah S. A comparison of cone beam computed tomography and ridge mapping in treatment planning of dental implants. Isra Med J. 2020; 12:87-90.

4. Ahmed N, Abbasi MS, Alavi FB, Naz A, Masood S, Irfan AB. Factors influencing the treatment options for single missing tooth: A patient preference based study. Isra Med J. 2021; 13:

5. Pjetursson BE, Tan K, Lang NP, Brägger U, Egger M, Zwahlen M. A systematic review of the survival and complication rates of fixed partial dentures (FPDs) after an observation period of at least 5 years: I. Implant-supported FPDs. Clin Oral Implants Res. 2004;15:625-42. https://doi.org/10.1111/j.1600-0501.2004.01117.x

6. AlMogbel AA, AlOlayan AA, AlFazwan AA. Assessment of the complications associated with tooth-supported fixed dental prosthesis at Qassim Region, Saudi Arabia. Int J Med Res Prof. 2017;3:93-5.

7. Özçakir Tomruk C, Özkurt-Kayahan Z, Sençift K. Patients' knowledge and awareness of dental implants in a Turkish subpopulation. J Adv Prosthodont. 2014:1;6:133-37.

https://doi.org/10.4047/jap.2014.6.2.133

8. Al-Wahadni A, Barakat MS, Abu Afifeh K, Khader Y. Dentists' most common practices when selecting an implant system. J Prosthodont. 2018;27:250-59.

https://doi.org/10.1111/jopr.12691

9. Pjetursson BE, Heimisdottir K. Dental implants-are they better than natural teeth?. Eur J Oral Sci. 2018;126:81-7.

https://doi.org/10.1111/eos. 12543

10. Rathod V, Shaikh MIK, Talreja P, Adhyaru H, Mukherjee S, Langade D. Awareness about dental implants amongst dental practitioners in Navi Mumbai: a knowledge, attitude and practice study. Int J Recent Sci Res. 2018:8;17013-018.

https://doi.org/10.24327/ijrsr.2017.0805.0265

11. Sheth TS, Shah SS, Thakore DS, Shah MN. Contemporary dental implant knowledge and attitude: A perspective of budding dentists. J Dent Implant:2017:7:54-8. 
Ahmed N/ Abbasi MS/ Mariam Q/ William H/ Iftikhar H/ Badar H/ Irfan AB

12. Dhami, B., Shrestha, P., Lamichhane, B., Sharma, A., \& Gupta, S. Dental Implants and General Dental Practitioners of Nepal: A study of existing knowledge and need for further education. J Coll Med SciNepal, 2017:13;212-15.

https://doi.org/10.3126/jcmsn.v13i1.16668

13. Khan MF, Khan FN, Ali I, Ahmed MR, Jawed R, Zahoor Q. Contemporary Trends Regarding Knowledge And Practices Of Dental Implants Among Dental Interns Working In Educational Institutes Of Karachi, Pakistan. J Bahria Uni Med Dental Coll: 2020;10:35-9

14. Sohail M, Aslam H, Ahmed N, Faruqui S, Maqsood A, Ansari MA, Buksh HA. Awareness, knowledge and reluctance regarding dental implants. Dentist. 2016;15:15-0.

15. Davis DM. The shift in the therapeutic paradigm: osseointegration. J Prosthet Dent. 1998:1;79:37-42. https://doi.org/10.1016/S0022-3913(98)70191-X

16. Ahmed N, Faruqui S. Factors affecting dental prosthesis satisfaction in Pakistani population. Int J Dent Res 2015;3:24. https://doi.org/10.14419/ijdr.v3i2.5439

17. Ghani F, Moeen F, Nisar S. Patients' Knowledge and Awareness Levels for Implant- Supported Dental Prostheses at a Teaching Dental Hospital. J Pak Dent Assoc 2013;22:78-83.

18. Parr GR, Gardner LK, Toth RW. Titanium: the mystery metal of implant dentistry. Dental materials aspects. J Prosthet Dent. 1985:1;54:410-14.

https://doi.org/10.1016/0022-3913(85)90562-1

19. Khan FR, Ali R, Nagi SE. A review of the failed cases of dental implants at a university hospital in Karachi. J Pak Med Assoc. 2016;66:S-24.

20. Ramanauskaite A, Roccuzzo A, Schwarz F. A systematic review on the influence of the horizontal distance between two adjacent implants inserted in the anterior maxilla on the inter-implant mucosa fill. Clin Oral Implants Res. 2018;29 Suppl 15:62-70. PMID: 29498128. https://doi.org/10.1111/clr.13103
Analysis of dental practitioners perception towards dental implants

21. Gastaldo JF, Cury PR, Sendyk WR. Effect of the vertical and horizontal distances between adjacent implants and between a tooth and an implant on the incidence of interproximal papilla. J Periodontol. 2004; 75:1242-46.

https://doi.org/10.1902/jop.2004.75.9.1242

22. Liaw K, Delfini RH, Abrahams JJ. Dental Implant Complications. Semin Ultrasound CT MR. 2015;36:427-33. Epub 2015 Oct 9. PMID: 26589696

https://doi.org/10.1053/j.sult.2015.09.007

23. Porter JA. Success or failure of dental implants? A literature review with treatment considerations. Gen Dent. 2005;53:423-32.

24. Hanif A, Qureshi S, Sheikh Z, Rashid H. Complications in implant dentistry. Eur J Dent. 2017;11:135.

https://doi.org/10.4103/ejd.ejd_340_16

25. Sharma A, Chaudhari BK, Shrestha B, Suwal P, Parajuli PK, Singh RK, Niraula SR. Knowledge and perception about dental implants among undergraduate dental students. BDJ Open. 2019:14;5:1. https://doi.org/10.1038/s41405-018-0009-1

26. Petropoulos VC, Arbree NS, Tarnow D, Rethman M, Malmquist J, Valachovic R, Brunson WD, Alfano MC. Teaching implant dentistry in the predoctoral curriculum: a report from the ADEA Implant Workshop's survey of deans. J Dent Educ. 2006;70:580-88.

https://doi.org/10.1002/j.0022-0337.2006.70.5.tb04114.x

27. Schönwetter DJ, Law D, Mazurat R, Sileikyte R, Nazarko O. Assessing graduating dental students' competencies: the impact of classroom, clinic and externships learning experiences. Eur J Dent Educ. 2011;15:142-52.

https://doi.org/10.1111/j.1600-0579.2010.00648.x

28. Lone MM. A Survey on Oral Implantology Education in the Dental Colleges of Pakistan. J Pioneering Medi Sci. 2016;6.17 